\title{
Influence of carbon emission on properties of YAG porous ceramics
}

\author{
Ming-Han $X u^{1}$, Jie-Guang Song ${ }^{1 a}$, Yang-Liang $\mathrm{Li}^{1}$, Wen-Tao $\mathrm{Li}^{1}$, Ting $\mathrm{Xu}{ }^{1}$ \\ ${ }^{1}$ Engineering \& Technology Research Center for Materials Surface Remanufacturing of Jiangxi \\ Province, School of Mechanical and Materials Engineering, Jiujiang University, Jiujiang 332005, \\ China \\ asongjieguang@163.com
}

Keywords: YAG porous ceramics, carbon emission temperature, microstructure, porosity, compressive strength.

\begin{abstract}
Due to some excellent properties of YAG, it is researched and applied widely. The YAG porous ceramics are prepared via the vacuum sintering technology. The results show that a certain relationship is existed between carbon emissions time and increasing temperature speed, increasing temperature speed is faster, carbon emission time is shorter, entire sintering cycle is shorter, which makes porosity similar, but higher compressive strength is shown, therefore, the increasing temperature speed slightly faster is advantageous to the performance of YAG porous ceramics, that is to say the heating rate of $5^{\circ} \mathrm{C} / \mathrm{min}$. By appearance, porosity, compressive strength performance comparison that carbon emissions at $800^{\circ} \mathrm{C}$ is more appropriate, porous ceramic YAG prepared under $1500^{\circ} \mathrm{C}$ and $1 \mathrm{~h}$ shows the white surface, $59.4 \%$ porosity and compressive strength of $8.55 \mathrm{MPa}$.
\end{abstract}

\section{Introduction}

Yttrium aluminum garnet (YAG) have excellent optical properties, chemical stability and good high temperature performance, both in structural materials or in the use of functional material have been widely used [1]. However, due to the large size of the YAG single crystal growth it requires special equipment and complex process, long production cycle, high cost, high rejection rate, thus limiting their wider use. Compared with the single crystal YAG transparent ceramic preparation process is simple, low cost, so it can be more reports of research into the desired size and shape, easy to achieve mass production, according to the device requirements. In addition, YAG ceramics prepared has good chemical stability, optical properties and high temperature performance [2-3], and in some cases their performance over a single crystal, become very competitive alternative to single crystal laser material [4]. YAG is one of the oxide material currently known better anti-creep properties. YAG until $1600^{\circ} \mathrm{C}$ fracture stress changes are not large, YAG high-temperature oxidizing atmosphere is also very stable, for 100 hours without any weight change. Thus, YAG is also considered one of the high-temperature structural materials of candidate materials [5].

Because all of the outstanding characteristics of YAG, with the preparation of porous ceramics and develop its performance is expected to improve in terms of high temperature catalytic filter and even replace the current porous ceramic materials, there is no relevant research studies reported YAG porous ceramics, the paper Effect of sintering process of the porous ceramic YAG performance, provide a reference for the synthesis of high-quality porous ceramic YAG.

\section{Experimental materials and methods}

The main raw material includes aluminum nitrate $\mathrm{Al}\left(\mathrm{NO}_{3}\right) \cdot 9 \mathrm{H}_{2} \mathrm{O}(\mathrm{AR})$, yttrium nitrate $\mathrm{Y}\left(\mathrm{NO}_{3}\right)$ - $6 \mathrm{H}_{2} \mathrm{O}(\mathrm{AR})$, ammonia, a sintering aid and a foaming agent. YAG powder by co-precipitation of pure standby preparation obtained. Add the $\mathrm{YAG}$ powder sintering aids $(\mathrm{CaO}, 5 \mathrm{wt} \%)$ and a foaming agent $(15 \mathrm{wt} \%)$, ball milling mixing evenly, using dry pressing technology to prepare YAG porous ceramic body $(\Phi 10 \times 5 \mathrm{~mm})$, the blank body temperature in a vacuum carbon tube furnace, using different sintering process for preparing a porous ceramic YAG get aside. 
TESCAN VEGA type II using scanning electron microscope YAG ceramic porous microstructure (SEM). Using AGS-5KNJ Universal mechanical testing machine YAG porous ceramic compressive strength testing. Volume density test method using YAG porous ceramics, and ceramic theoretical density compared to calculate porosity porous ceramic YAG.

\section{Results and discussion}
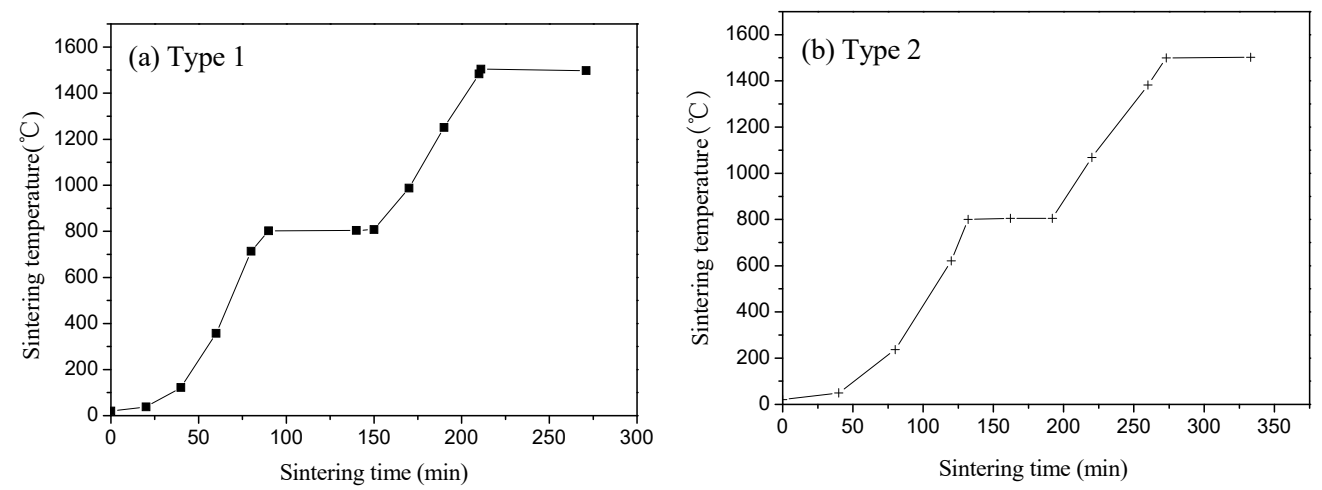

Fig. 1 The different heating type prepared porous ceramic YAG

Fig. 1 shows a heating mode relationship between the sintering temperature and sintering time, from the Fig.1, two samples were at $800^{\circ} \mathrm{C}, 1500^{\circ} \mathrm{C}$ each incubated for 1 hour, the increasing temperature speed of type 2 is slower than that of type 1 to get the same temperature, the required time of heating mode 2 is longer than that of heating mode 1. Can also be seen from the figure, the temperature rise early, a heating rate of change is relatively slow, , the time and temperature changes nearly linearly changes with the continued extension of time, sintering temperature and time changes linearly during sintering late stage.

Tab.1 Performance of porous ceramic YAG prepared with different heating rate

\begin{tabular}{c|c|c|c}
\hline Heating type & Density $\left(\mathrm{g} / \mathrm{cm}^{3}\right)$ & Porosity $(\%)$ & Compressive strength $(\mathrm{MPa})$ \\
\hline 1 & 1.388 & 56.3 & 3.68 \\
\hline 2 & 1.302 & 59.1 & 2.70 \\
\hline
\end{tabular}

Tab.1 shows the performance of YAG porous ceramic prepared with different heating rate, it can be seen from the Tab.1, the higher density and the lower porosity of sample prepared with mode lare shown, the type 2 is contrary result, the mainly is the soluble starch decomposed into $\mathrm{H}_{2} \mathrm{O}$ and $\mathrm{CO}_{2}$ and other gases under high temperature, the heating rate of heating mode 1 is faster, the decomposition gas speed of soluble starch is faster, gas flow rate is faster, which scours powder to strengthen the role of body resulting in the shedding of particles, these particles fall and blocked some of the holes, which is not conducive to the discharge of gases such as $\mathrm{H}_{2} \mathrm{O}$ and $\mathrm{CO}_{2}$, while the particles of filled holes made by the decomposition of soluble starch, such that the density of the sintered ceramic increases, the porosity decreases.

Fig. 2 shows a microstructure of YAG ceramic porous prepared with different heating rate, it can be seen from the Fig.2, the pore of Fig2-a is small, irregular and most of the hole was closed cell, the pore of Fig2-b is relatively large, the main macroporous exists in the ceramics, particles have grown up together, there are some parts of micropores. The main reason for these phenomena are that the decomposition of soluble starch is rapidly wih warming faster mode, faster carbon emission occurred the microstructure of Fig.2-a. A heating rate of Fig.2-b is slower, carbon emission rate is relatively slower, some microporous appears in the matrix, the particles combined with sufficient time and carbon emissions slowly eliminated along certain channels, so there are some big pores between the particles. From the Fig.2, the bonding surface between the particles is relatively large and not as (b) the figure some big holes, and therefore the compressive strength of the sample prepared with faster heating is higher than the compressive strength of the sample prepared with slower heating. 

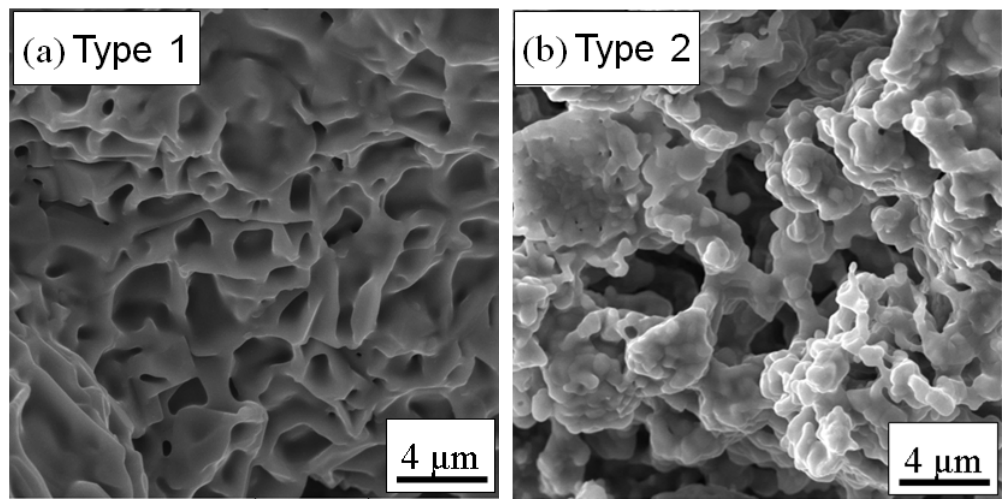

Fig.2 Effect of heating rate on microstructure of porous ceramic YAG

Tab.2 Performance of YAG porous ceramics prepared with different carbon emission temperature

\begin{tabular}{|c|c|c|c|}
\hline $\begin{array}{c}\text { Carbon emission temperature } \\
\qquad\left({ }^{\circ} \mathrm{C}\right)\end{array}$ & $\begin{array}{l}\text { Density } \\
\left(\mathrm{g} / \mathrm{cm}^{3}\right)\end{array}$ & $\begin{array}{l}\text { Porosity } \\
(\%)\end{array}$ & $\begin{array}{c}\text { Compressive strength } \\
(\mathrm{MPa})\end{array}$ \\
\hline 800 & 1.289 & 59.4 & 8.55 \\
\hline 1000 & 1.355 & 57.3 & 5.68 \\
\hline (a) $800^{\circ} \mathrm{C}$ & & $000^{\circ} \mathrm{C}$ & \\
\hline & $4 \mathrm{~mm}$ & & $4 \mathrm{~mm}$ \\
\hline
\end{tabular}

Fig.3 Surface topography of sample prepared with different carbon emission temperature

Tab.2 shows the performance of YAG porous ceramics prepared with different carbon emission temperature, it can be seen from the Tab.1, the lower density of sample of carbon emissions at $800^{\circ} \mathrm{C}$ than $1000^{\circ} \mathrm{C}$, the porosity shows the opposite result, the main reason for this phenomenon is that YAG porous ceramic is sintered by vacuum sintering method, the soluble starch is decomposed above $800^{\circ} \mathrm{C}$, but a lower temperature is shown in the furnace $800^{\circ} \mathrm{C}$, it does not produce the glass phase in the green body at that temperature, it resulting in discharge of carbon samples can be carried out smoothly, and when the carbon emissions temperature is $1000^{\circ} \mathrm{C}$, the green body at this temperature the formation of a glass phase that is liquid in the high temperature furnace, the gas difficult to discharge from decomposed soluble starch in the green body. We can also be seen from the Tab.2, the compressive strength of $800^{\circ} \mathrm{C}$ carbon emissions is higher than $1000^{\circ} \mathrm{C}$, which may be due, at $1000^{\circ} \mathrm{C}$ high temperature of exhaust carbon crystal body and acts as a nucleation role in promoting the sample particles in the sample sintered at high temperatures and is easy to grow up together secondary recrystallization cause abnormal grain growth, so that the mechanical properties of the sample of coarse grains is deteriorated.

Fig. 3 is a carbon emissions under different temperature sintered sample digital photos, the picture can be seen from the sample surface at $800^{\circ} \mathrm{C}$ carbon emission appear white, carbon emission surface of the sample $1000^{\circ} \mathrm{C}$ is black, the surface can be well explained the difference porosity in Tab.2, $1000^{\circ} \mathrm{C}$ discharge carbon black surface mainly because of the emergence of a sample glass phase at $1000^{\circ} \mathrm{C}$, the gas is discharged from the blank body is not easy, so $1000^{\circ} \mathrm{C}$ does not $800^{\circ} \mathrm{C}$ carbon emissions full under the same conditions. We can also be seen from the Fig.3, the surface of the sample using $1000^{\circ} \mathrm{C}$ carbon emission shows melten phase, which may be due to $1000{ }^{\circ} \mathrm{C}$ carbon emissions, the higher sintering temperature produces a catalytic role to reduce the crystallization temperature. 

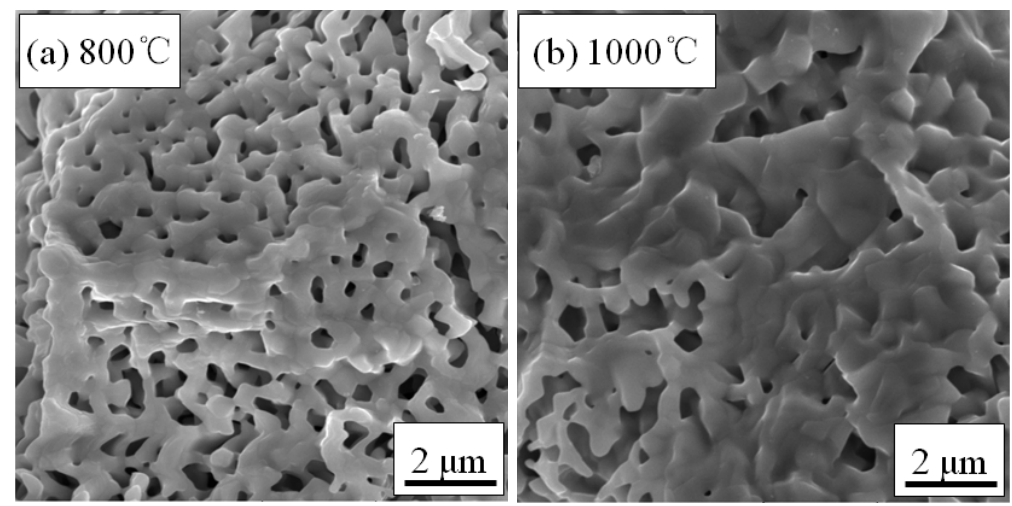

Fig.4 Microstructure of sample prepared with different carbon emission temperature

Fig.4 is the microstructure of sample prepared with different carbon emission temperature, we seen from the Fig.4, the $800^{\circ} \mathrm{C}$ carbon emission was obtained more uniform pore structure than the $1000^{\circ} \mathrm{C}$ carbon emissions, which indicates that $1000^{\circ} \mathrm{C}$ is not conducive prefabricated body of carbon emissions. Microstructure of $1000^{\circ} \mathrm{C}$ discharge of carbon particles together forming small pores, so prone to abnormal growth of aggregate grains, not conducive to improving the mechanical properties of ceramics. We can also be seen from the Fig. $4,1000^{\circ} \mathrm{C}$ carbon emissions can reduce the sintering temperature. By contrast appearance, porosity, compressive strength performance that carbon emissions at $800^{\circ} \mathrm{C}$ is more appropriate.

\section{Summary}

The results show that a certain relationship is existed between carbon emissions time and increasing temperature speed, increasing temperature speed is faster, carbon emission time is shorter, entire sintering cycle is shorter, which makes porosity similar, but higher compressive strength is shown, therefore, the increasing temperature speed slightly faster is advantageous to the performance of YAG porous ceramics, that is to say the heating rate of $5^{\circ} \mathrm{C} / \mathrm{min}$. By appearance, porosity, compressive strength performance comparison that carbon emissions at $800^{\circ} \mathrm{C}$ is more appropriate, porous ceramic YAG prepared under $1500^{\circ} \mathrm{C}$ and $1 \mathrm{~h}$ shows the white surface, $59.4 \%$ porosity and compressive strength of $8.55 \mathrm{MPa}$.

\section{Acknowledgements}

The authors are thankful for the financial support provide by the Science and Technology Found of the Educational Department of Jiangxi Province, China(KJLD12096) and the Science and Technology Found of Jiujiang University, China (2014KJYB016).

\section{References}

[1] R. Marder, C. Estournes, G. Chevallier, Spark and plasma in spark plasma sintering of rigid ceramic nanoparticles:A model system of YAG, J. Eur. Ceram. Soc. 35 (2015) 211-218.

[2] Y.H. Huang, D.L. Jiang, J.X. Zhang, Sintering kinetics of YAG ceramics, J. Rare Earth. 32 (2014) 416-422.

[3] J.G. Song, F. Wang, M.H. Xu, Effect of synthesis conditions on the particle size and morphology of YAG powder, J. Ceram. Proc. Res. 13 (2012) 154-157.

[4] Z. Song, J. Liao, Q.L. Liu, Synthesis of YAG phosphor particles with excellent morphology by solid state reaction, J. Crys. Growth. 365 (2013) 24-28.

[5] G. He, G.H. Liu, Z.C. Yang, S.B. Guo, J.T. Li, Preparation of YAG glass-ceramic by combustion synthesis under high gravity, Ceram. Int. 40 (2014) 15265-15271. 